\title{
The Effectiveness of the Primary Trauma Care Courses in West Bank, Palestine: Are the Outcomes Acceptable?
}

\author{
Abdallah Alwawi $^{1^{*}} \quad$ Nawaf Amro ${ }^{2} \quad$ Bahar Inkaya $^{3}$ \\ 1. RN, Candidate PhD. Ankara Yıldırım Beyazıt University, Turkey \\ 2. MS(c). Faculty of Nursing- Al Zaytoonah University of Jordan, Jordan \\ 3. PhD. Faculty of Health Sciences, Yıldırım Beyazıt University, Turkey
}

\begin{abstract}
Background: Injuries in all shapes are accounting for more than five million deaths worldwide. Road traffic accidents injuries are the main threat to people and national health systems. Annually, road traffic injuries are resulting in the deaths of more than five million people globally. The Primary Trauma Care Foundation was organized to run the workshop for front-line staff in such countries to attempt and decrease the human and economic consequence of the injury. Methods: A one group pre-test and post-test experimental research design was used. Subjects were invited to complete a multiple-choice question. The overall number of subjects who were taking the primary trauma care course during the period (from Jun 2014 to Oct 2017) was 586 subjects. Results: More than two-thirds of subjects were men and doctors included specialties, physicians and medical students. (90.8\%) of participants were carried bachelor's degree. $(22.2 \%)$ were staff nurses and nurse's students, $(1.9 \%)$ were midwives. Wilcoxon Signed Ranks Test shows a statistically significant difference between pre and post course score of PTC knowledge $(\mathrm{p}<0.001) .567(96.75 \%)$ of the participants were shown an improvement after a PTC course. Conclusion: PTC course in Palestine is a valuable and informative course to increase and improve knowledge toward physicians, staff nurses, and midwives.
\end{abstract}

Keywords: Primary Trauma Care (PTC), Effectiveness, Emergency, Palestine.

DOI: $10.7176 / \mathrm{JEP} / 10-9-12$

Publication date:March $31^{\text {st }} 2019$

\section{Introduction}

Injuries in all shapes are accounting for more than five million massive deaths throughout the world(Lopez et al., 2006). The injury is a major inducer of morbidity and mortality through the world, moving into individual, the young and good people who are the central breadwinners(Ozgediz et al., 2008, Nogaro et al., 2015). In addition, Road Traffic Accidents (RTA) injuries are a major danger to public individuals and national health systems. Yearly, RTA injury outcome more than five million people died throughout the world(Delavar et al., 2012, Amro and Qtait, 2017). Africa stands a large burden, with more deaths happening yearly from wounds and injuries (either accidents or violence)(Nogaro et al., 2015). Ninety percent of injuries related deaths happen in low and middleincome countries for example Kenya. In an observational study of community emergency centers in Kenya in 2011, trauma was the second greatest common presenting complaint(Wachira et al., 2012). In 2017, 194 cases were dead due to RTA in Palestine. Moreover, incident rate of work injuries among Palestinian's in the West Bank was 69.1 per 100.000 populations, while it was 61.9 per 100.000 of the population in 2016. (MOH, 2017). Furthermore, the highest percentage of work injuries were recorded in the 15-24 age groups, followed by the 2534 age groups(MOH, 2017).

Studies have revealed that training Advanced Trauma Life Support (ATLS) to healthcare providers leads to important rises in information, knowledge, and skill and is well established(Ali et al., 1998). To provide consistently good trauma care in developing countries, the ATLS protocol is well recognized and extensively adopted. But, although the ATLS values are generally applicable, the viability and practicality of this method in low, middle countries (LMICs) are less evident. Barriers contain the lack of planned healthcare infrastructure, staff, funding, and education(House et al., 2014). Knowing the inequality between the need for and provision of training in trauma management in LMICs, the Primary Trauma Care Foundation (PTCF) was structured in 1997 to track courses for front-line staff in such countries to attempt and decrease the human and economic effect of injuries(House et al., 2014). And the setup for health care providers to do essential assessment, evaluation and management of the harshly injured patient at the District Hospital level, with both restricted properties and manpower(Foundation, 2018). Training is based on ATLS principles, but adapted to appropriate the restricted resources in LMICs(Nogaro et al., 2015) Furthermore, systematic review has revealed that such short trauma courses give a significant reduction in mortality(Meaney et al., 2010). Moreover, the course has been shown to expand provider knowledge and to confer long-lasting skills on the organized and priority-based approach to the injured patient(Mohammad et al., 2014).

In the west bank, the number of health-related visits to the emergency services in the Ministry of Healthaffiliated hospitals were 864,613(MOH, 2016). Palestinians in the West Bank have been living under long military occupation, this occupation affected all aspects of people's lives and still forms a real challenge for Palestinians 
health and the entire healthcare system(Amro et al., 2018). Palestinian emergency services are carried out under enormous pressure, with inadequate human resources and lack of medical equipment and supplies. The demand on health services significantly increases with the increased intensity of Israeli violence against Palestinians. The healthcare organization is overwhelmed by the influx of injuries and traumas in Palestine. These situations are considered emotionally and physically challenging for healthcare workers in emergency departments(Amro et al., 2018).

Despite this, Palestine has no organized system of trauma care and clinicians and lack specific training on the systematic management of the acutely injured patient. In its guidelines for crucial trauma care, the World Health Organization (WHO) recommends short, resource-specific trauma courses for providers working in low-income countries(Mock, 2004). After deep searchers regarding PTC studies, there is no studies conducted before in Palestine. Consequently, this study was carried out to find how useful are primary trauma care courses in Palestine.

\section{Materials and Methods}

2.1 Study design and population

A one group pre-test and post-test experimental research design was used. The PTC two-days course, which is open to all levels of healthcare practitioners included doctors (specialties, physicians and medical students), nurses (Staff nurses and nursing students) and midwifery.

\subsection{Sample size}

The total number of subjects who were taking the PTC course throughout the period (from Jun 2014 to Oct 2017) was 586 subjects from all West Bank cities by invitation or application regarding the PTC course.

\subsection{Data collection and measurement}

Subjects were demanded to complete a Multiple-Choice Questions (MCQ) at the start and end of each course in four years duration. This contained a demographic variable such as gender, level of education and occupation, then a set of 20 questions related to trauma which subjects had up to $30 \mathrm{~min}$ to complete it. One point was given for every correct answer out of 5 options. There was no negative marking. Subjects were requested to complete the same set of questions at the end of the two days course. The MCQ was compiled from a list of questions within the PTC manual and the database that have been extensively used in PTC courses(Foundation, 2016). The MCQ was presented in an unbiased manner according to the best practice guidelines of writing MCQ.

\subsection{Pilot study}

A 15 subjects matching the inclusion criteria for the study finished the survey as a pilot study before collecting actual original data. The essential aim of the pilot study was to determine the interpretability of the questions, estimate the length of time it would take to finish the questionnaire. All participants in the pilot study indicated that the instrument was clear and they were able to finish the questionnaire within twenty minutes. Items were tested for reliability in the current study and the results shown that the cronbach's alpha coefficient was 0.76 .

\subsection{Statistical Analysis}

Data were analyzed using the SPSS program version 24. Descriptive statistics were used to find percentages and the mean score of pre-test and post-test for subjects. Non-parametric test Wilcoxon Sign Rank test was used to find out the significant difference between pre and post-test score. A p-value of $<0.05$ was considered statistically significant.

\subsection{Ethical considerations}

The study was a non-invasive and did not source any physical damage. All subjects enrolled in this study gave written consent for their scores to be used in this analysis. Informed consent from data collection settings was obtained. The committee of research at Al-Quds University approved the study. The confidentiality and anonymity of the obtained data were totally protected by providing code numbers for each subject.

\section{Results}

A total of 586 participants filled out the self-administered questionnaire. Table 1 gives a review of the subjects including demographic variables and general characteristics. More than two-thirds of subjects were men and doctors included physicians and medical students, (90.8\%) of participants were carried bachelor's degree, $(22.2$ $\%)$ were staff nurses and nurse's students, $(1.9 \%)$ were midwives. 
Table 1. Demographic variables

\begin{tabular}{|l|c|c|}
\hline Variables & n & \% \\
\hline Gender & 377 & 64.3 \\
\hline Male & 209 & 35.7 \\
\hline Female & 41 & 7.0 \\
\hline Level of education & 532 & 90.8 \\
\hline Diploma & 13 & 2.2 \\
\hline Bachelor's & \multicolumn{2}{|l|}{} \\
\hline Master degree & 445 & 75.9 \\
\hline Occupation & 130 & 22.2 \\
\hline Doctors (specialties, physicians and medical students) & 11 & 1.9 \\
\hline Nurses (Staff nurses and nursing students) &
\end{tabular}

Table 2. Wilcoxon Signed Ranks Test shows a statistically significant difference between pre-course and post-course score of PTC knowledge $(\mathrm{p}<0.001)$. The mean total score before the course was 9.43 over 20 and after the course was 15.70 over 20 . In addition, $567(96.75 \%)$ of the participants were shown an improvement after a course, where $14(2.38 \%)$ participants demonstrated no change, while $5(0.85 \%)$ participants were shown no improvement in MCQ scores.

Table 2. Improvement in scores before and after PTC course.

\begin{tabular}{|l|c|c|c|c|c|c|c|}
\hline & n & Mean & Minimum & Maximum & \pm & Z value & P value \\
\hline Pre-test & 586 & 9.43 & 1 & 19 & 2.96 & \multirow{2}{*}{-20.72} & $<0.001$ \\
\hline Post-test & 586 & 15.76 & 5 & 20 & 2.92 & \\
\hline
\end{tabular}

Wilcoxon Signed Ranks Test

Men achieved a higher MCQ's score in both pre- and post-course compared to women ( 9.66 for men vs 9.02 for women) pre-course, and (16.08 for men vs 15.18 for women) post-course, p-value 0.020 , respectively. Participants who were carried master degree achieved a higher score MCQ's in pre-course (10.38 for master degree vs 9.68 for bachelor's and 5.92 for diploma), p-value $<0.001$, respectively. Moreover, Participants who were carried bachelor's degree achieved a higher score MCQ's in post-course (16.05 for bachelor's degree vs 16 for master and 11.97 for diploma), $p$-value $<0.001$, respectively. Doctors achieved a higher MCQ's score both pre- and postcourse compared to staff nurses and midwives (9.98 for doctor's vs 7.73 for staff nurses and 7.36 for midwives) pre-course, and (16.47 for doctor's vs 13.56 for staff nurses and 13.09 for midwives) post-course, $p$-value $<0.001$ respectively.

Table 3. Differences between demographic variables before and after the course in term of PTC knowledge.

\begin{tabular}{|c|c|c|c|c|c|c|}
\hline \multicolumn{7}{|l|}{ Gender } \\
\hline & variables & $\mathbf{n}$ & Mean & \pm & $t(d f)$ & P value \\
\hline \multirow[t]{2}{*}{ Pre-test } & Male & 377 & 9.66 & 2.67 & \multirow{2}{*}{$2.33(352)$} & \multirow{2}{*}{.020} \\
\hline & Female & 209 & 9.02 & 3.39 & & \\
\hline \multirow[t]{2}{*}{ Post test } & Male & 377 & 16.08 & 2.73 & \multirow{2}{*}{$3.45(380)$} & \multirow{2}{*}{$<.001$} \\
\hline & Female & 209 & 15.18 & 3.16 & & \\
\hline \multicolumn{7}{|c|}{ Level of education } \\
\hline & variables & $n$ & Mean & \pm & $F(d f)$ & P value \\
\hline \multirow[t]{3}{*}{ Pre-test } & Diploma & 41 & 5.92 & 2.07 & \multirow{3}{*}{$34.75(2)$} & \multirow{3}{*}{$<.001$} \\
\hline & Bachelor's & 532 & 9.68 & 2.86 & & \\
\hline & Master degree & 13 & 10.38 & 2.63 & & \\
\hline \multirow[t]{3}{*}{ post test } & Diploma & 41 & 11.97 & 3.55 & \multirow{3}{*}{$42.19(2)$} & \multirow{3}{*}{$<.001$} \\
\hline & Bachelor's & 532 & 16.05 & 2.66 & & \\
\hline & Master degree & 13 & 16.00 & 2.798 & & \\
\hline \multicolumn{7}{|c|}{ Occupation } \\
\hline & variables & $\mathbf{n}$ & Mean & \pm & $\mathbf{F}$ & P value \\
\hline \multirow[t]{3}{*}{ Pre-test } & Doctors & 445 & 9.98 & 2.79 & \multirow{3}{*}{$35.43(2)$} & \multirow{3}{*}{$<.001$} \\
\hline & Nurses & 130 & 7.73 & 2.82 & & \\
\hline & Midwifery & 11 & 7.36 & 2.87 & & \\
\hline \multirow[t]{3}{*}{ Post test } & Doctors & 445 & 16.47 & 2.53 & \multirow{3}{*}{$66.83(2)$} & \multirow{3}{*}{$<.001$} \\
\hline & Nurses & 130 & 13.56 & 2.99 & & \\
\hline & Midwifery & 11 & 13.09 & 2.42 & & \\
\hline
\end{tabular}




\section{Discussion}

Applied, actual and effective PTC course is essential, particularly in developing resource-constrained countries as unlike other trauma training courses, the PTC course is presented free to all countries wanting to use it. PTC manual and instructor packs are easily accessible on the website(Foundation, 2016). This study reports the results of the first Palestinian study about the PTC course. In this study, the results indicated that there is a significant increase in participants' knowledge after two days of PTC course. Overall, $567(96.75 \%)$ of the participants were shown an enhancement over a PTC course, the pre-test score was 9.43 and the post-test score was 15.76 over 20 with a mean difference $6.33(\mathrm{p}<0.001)$. This is the first in-depth analysis of the impact of the PTC course with candidates' knowledge and explores some of the factors involved.

There are many prior studies that have revealed similar results about the PTC course. A study conducted in 2011 in Pakistan discovered that there is a significant enhancement of subject knowledge after two days of PTC workshop $(p<0.001)$ (Jawaid et al., 2013). An additional study from Iran informed significant enhancement in knowledge after PTC workshop. In that study, the mean score on the pre-test was 18.84 and post-test was 26.72 $(\mathrm{p}<0.001)$, Furthermore, a study applied in 2013 in the Development Center of Tabriz Medical University has revealed that the mean score on the pre-test and post-test were 18.84 and 26.72 respectively $(\mathrm{P}<0.001)($ Amiri et al., 2013). And a study applied in 2017 in Kenya shown score means were $61.5 \%$ pre-course and $76.9 \%$ postcourse, mean difference $15.5 \%(\mathrm{p}<0.001)$ (Wanjiku et al., 2017).

In our study, the results indicated that men achieved a higher MCQ score in both pre and post-test and there is a significant score improvement between gender $(\mathrm{p}<0.020)$ and $(\mathrm{p}<0.001)$ respectively. Master degree achieved the highest MCQ score in pre-test $(\mathrm{p}<0.001)$ and Bachelor's degree achieved a higher MCQ score in the post-test $(\mathrm{p}<0.001)$. In addition, doctors achieved a higher MCQ score in both pre and post-test and there is a significant difference in score improvement between occupation $(\mathrm{p}<0.001)$ and $(\mathrm{p}<0.001)$ respectively.

In analyzing the effect of gender, the first notable difference is the high percentage of men compared to women who have taken a place in the PTC course with a ratio of 2:1. Furthermore, in Palestine, most emergency medical technician are male doctors, and nurses. Consequently, females in emergency situations are more soft, sensitive and being more reactive to the emotional images and situation(Magaldi, 2015). In term of level of education, as predictable in pre-course master degree achieved higher scores than others, but in post-course bachelor's degree achieved a little bit higher score than the master, the reason could be that most subjects are carried bachelor's degree (90.8\%) included medical and nurse's students. Analysis of scores based on the occupational background revealed that doctors (which including specialties, physicians, medical students achieved a higher pre- and post-course scores compared to staff nurses and midwifery. But, importantly, both groups show a significant improvement in score. This endorses the necessity for continuing training of doctors, as despite holding a higher medical degree these subjects seem to advantage from participating in the course. Secondly, Doctors took full courses during their studies on critical care and emergency care in details. But nurses and midwives do not take them in details. Furthermore, subjects included some specialties may increase the mean score of knowledge. Finally, it supports the opinion that the PTC course is appropriate and valuable to all healthcare workers(Nogaro et al., 2015). This is of prime importance, specifically in areas of the world where there is a great lack of medical personnel. For instance, Malawi, with a population of 14 million has only 10 orthopedic surgeons(Nogaro et al., 2015).

\section{Conclusion}

The two days of Primary Trauma Care (PTC) course in Palestine is a beneficial, valuable and informative course to improve knowledge in PTC. Nevertheless, of occupational background, level of education and gender.

\section{Limitation}

This study inherent limitation that must be taken into consideration. Firstly, the study not evaluated the Gaza strip in Palestine. Secondly, the study not evaluated the skills part. Finally, this study not funded.

\section{Recommendation}

Researchers recommended to give a PTC course for all healthcare providers and non-healthcare providers (included bus, taxi and lorry drivers, school and university teachers who are exposed to a large number of people and likely to be among the first-responders to trauma patients, may be beneficial in improving trauma patient outcomes especially in countries where pre-hospital services are scarce.

\section{Acknowledgment}

Authors acknowledge the governmental hospitals for cooperation with us and appreciate the confidentiality for giving us the data set related to participants. 


\section{Conflict of interests}

The authors declare that they have no conflict of interests.

\section{Authors' Contribution}

Authors were involved actively in planning and supervised the work of the study. All listed researchers collectively performed the analysis, drafted the manuscript and designed the tables. The researchers interpreted the results and worked on the manuscript.

\section{References}

ALI, J., COHEN, R. J., GANA, T. J. \& AL-BEDAH, K. F. 1998. Effect of the Advanced Trauma Life Support program on medical students' performance in simulated trauma patient management. Journal of Trauma and Acute Care Surgery, 44, 588-591.

AMIRI, H., GHOLIPOUR, C., MOKHTARPOUR, M., VAHDATI, S. S., AGHDAM, Y. H. \& BAKHSHAYESHI, M. 2013. Two-day primary trauma care workshop: early and late evaluation of knowledge and practice. European Journal of Emergency Medicine, 20, 130-132.

AMRO, N., KAMEL, A. M. A., QTAIT, M., YAGI, H., AMRO, B., AMRO, R. \& AMRO, R. 2018. Factors Affect Patients Satisfaction in Emergency Departments in Palestine. Journal of Health, Medicine and Nursing, 54, 50-56.

AMRO, N. R. \& QTAIT, M. 2017. General Knowledge \& Attitude of First Aid among Schoolteacher's in Palestine. International Journal of Innovative Research in Medical Science, 2, 660 to 665-660 to 665.

DELAVAR, M. A., GHOLAMI, G., AHMADI, L. \& MOSHTAGHIAN, R. 2012. Knowledge, attitude and practices of relief workers regarding first aid measures. Education, 25, 59.2-16.1.

FOUNDATION, P. T. C. 2016. DOWNLOAD RESOURCES [Online]. Oxford OX1 9PG, UK. Available: https://www.primarytraumacare.org/get-involved/download-resources/ [Accessed].

FOUNDATION, P. T. C. 2018. WHAT WE DO [Online]. Available: https://www.primarytraumacare.org [Accessed].

HOUSE, D. R., NYABERA, S. L., YUSI, K. \& RUSYNIAK, D. E. 2014. Descriptive study of an emergency centre in Western Kenya: challenges and opportunities. African Journal of Emergency Medicine, 4, 19-24.

JAWAID, M., MEMON, A. A., MASOOD, Z. \& ALAM, S. N. 2013. Effectiveness of the primary trauma care course: is the outcome satisfactory? Pakistan journal of medical sciences, 29, 1265.

LOPEZ, A. D., MATHERS, C. D., EZZATI, M., JAMISON, D. T. \& MURRAY, C. J. 2006. Global burden of disease and risk factors, The World Bank.

MAGALDI, K. 2015. Women's Brains Are More Sensitive To Negative Emotions; React Differently Than Men's [Online]. Available: https://www.medicaldaily.com/study-womens-brains-are-more-sensitive-negativeemotions-react-differently-mens-354226 [Accessed].

MEANEY, P. A., TOPJIAN, A. A., CHANDLER, H. K., BOTHA, M., SOAR, J., BERG, R. A. \& NADKARNI, V. M. 2010. Resuscitation training in developing countries: a systematic review. Resuscitation, 81, 14621472.

MOCK, C. 2004. Guidelines for essential trauma care, World Health Organization.

MOH 2016. Director of Palestinian Health Information Center (PHIC). Ministry of Health.

MOH 2017. Director of Palestinian Health Information Center (PHIC). Ministry of Health

MOHAMMAD, A., BRANICKI, F. \& ABU-ZIDAN, F. M. 2014. Educational and clinical impact of Advanced Trauma Life Support (ATLS) courses: a systematic review. World journal of surgery, 38, 322-329.

NOGARO, M.-C., PANDIT, H., PETER, N., LE, G., OLORUNTOBA, D., MUGUTI, G. \& LAVY, C. 2015. How useful are primary trauma care courses in sub-Saharan Africa? Injury, 46, 1293-1298.

OZGEDIZ, D., JAMISON, D., CHERIAN, M. \& MCQUEEN, K. 2008. The burden of surgical conditions and access to surgical care in low-and middle-income countries. Bulletin of the World Health Organization, 86, 646-647.

WACHIRA, B. W., WALLIS, L. A. \& GEDULD, H. 2012. An analysis of the clinical practice of emergency medicine in public emergency departments in Kenya. Emerg Med J, 29, 473-476.

WANJIKU, G., JANEWAY, H., FOGGLE, J., PARTRIDGE, R., WANG, Y., KEARNEY, A., LEVINE, A. C., CARTER, J. \& TABU, J. S. 2017. Assessing the impact of an emergency trauma course for senior medical students in Kenya. African Journal of Emergency Medicine, 7, 167-171. 